\title{
Obtención de aceituna negra de mesa por fermentación en batch con cultivo iniciador
}

\author{
Obtaining black olive table by fermentation in batch with initiating culture
}

\author{
${ }^{1}$ Daladier Castillo Cotrina, ${ }^{2}$ Carlos Tito Vargas.
}

\begin{abstract}
RESUMEN
El objetivo fue obtener aceituna negra de mesa por fermentación en batch con y sin cultivo iniciador. Se empleó aceitunas negras de Olea europea var. sevillana, que fueron colocadas ( $4 \mathrm{~kg}$ por fermentador) en tres fermentadores conteniendo sal de cocina 10\%, a dos de los cuales se les agregó cultivo iniciador. Los fermentadores se incubaron a $\mathrm{T}^{\circ}$ $\mathrm{Ab}$. de laboratorio. Se evaluó durante la fermentación el $\mathrm{pH}$, la acidez, la concentración de sal, la temperatura y el número de bact. $\mathrm{ml}^{-1}$ de salmuera; y al término de la fermentación la producción, productividad y los atributos de apariencia externa, olor, sabor y textura. Se obtuvo aceituna negra de mesa en cuya fermentación (64 días) el pH tuvo una tendencia de descenso desde 6.0 a 4.0 ; la acidez una tendencia de ascenso de 0.1 a $2.01 \%$ en ácido láctico con mayor producción de acidez donde hubo cultivo iniciador; la concentración de sal una tendencia de mantenimiento constante entre 6.5 a $7.7^{\circ} \mathrm{Be}$ con un valor ligeramente menor donde hubo cultivo iniciador; la temperatura una tendencia de constancia entre 14 y $12{ }^{\circ} \mathrm{C}$; el $\mathrm{N}^{\circ}$ de bact $\mathrm{ml}^{-1}$ una tendencia inicial de incremento seguida de mantenimiento en un valor menor, con una ligera mayor concentración de bacterias donde hubo cultivo iniciador (4.3

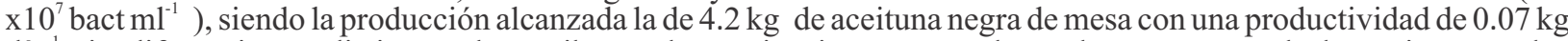
día $^{-1} \sin$ diferencia estadistica en los atributos de apariencia externa, olor, sabor y textura de la aceituna en los tratamientos con y sin cultivo iniciador.
\end{abstract}

Palabras clave: Aceituna negra de mesa, fermentación en batch, cultivo iniciador, salmuera.

\begin{abstract}
The objective was to obtain black table olives by batch fermentation with and without starter culture. Black olives of Olea europea var. Seville, which were placed (4 kg per fermenter) in three fermenters containing 10\% cooking salt, two of which were added starter culture. The fermenters were incubated at $\mathrm{T}^{\circ} \mathrm{Ab}$. from laboratory. The $\mathrm{pH}$, acidity, salt concentration, temperature and the number of bact $\mathrm{ml}^{-1}$ brine were evaluated during fermentation; and at the end of the fermentation the production, productivity and attributes of external appearance, smell, taste and texture. Black table olives were obtained in whose fermentation (64 days) the $\mathrm{pH}$ had a tendency of decrease from 6.0 to 4.0 ; acidity a tendency of ascent from 0.1 to $2.01 \%$ in lactic acid with higher acidity production where there was starter culture; the salt concentration a constant maintenance trend between 6.5 to $7.7^{\circ} \mathrm{Be}$ with a slightly lower value where there was starter culture; the temperature a trend of constancy between 14 and $12{ }^{\circ} \mathrm{C}$; No. of bact $\mathrm{ml}^{-1}$ an initial trend of increase followed by maintenance at a lower value, with a slightly higher concentration of bacteria where there was starter culture $\left(4.3 \times 10^{7}{\left.\text { bact } \mathrm{ml}^{-1}\right)}\right.$, the production being reached at $4.2 \mathrm{~kg}$ of black table olives with a productivity of $0.07 \mathrm{~kg}^{-1}$ without statistical difference in the attributes of external appearance, smell, taste and texture of the olive in treatments with and without starter culture.
\end{abstract}

Keywords: Black table olives, batch fermentation, starter culture, brine.

\footnotetext{
${ }^{1}$ Universidad Nacional Jorge Basadre Grohmann. Tacna - Perú. E-mail: daladiercastillo@hotmail.com

${ }^{2}$ Universidad Nacional Jorge Basadre Grohmann. Tacna - Perú. E-mail: ctitov@unjbg.edu.pe 


\section{INTRODUCCIÓN}

Las plantas de olivo (Olea europea) corresponden a diferentes tipos de variedades. El fruto puede ser sometido a fermentación para obtener lo que se llama aceituna fermentada que es un alimento consumido por el hombre (Brock 2012). A este alimento se le llama aceituna de mesa. Existen diferentes variedades de aceituna de mesa. Una de ellas es la aceituna negra de mesa (Bernabé 2003, Garrido \& García 1988).

La aceituna negra de mesa es un producto que se obtiene por fermentación anaeróbica del fruto del olivo (Frazier \& Westhoff 1993).

La fermentación de aceituna puede realizarse bajo diferentes procesos, una de ellas es bajo el proceso en batch. En esta fermentación los microorganismos juegan un papel preponderante, estos pueden encontrarse en el fruto del olivo y ser ellos mismos los que realicen la fermentación; también pueden proceder de otras fermentaciones de aceituna que son agregadas entonces como cultivo iniciador al fermentador en la cual se realizará la fermentación de aceituna. Los cultivos iniciadores se ha determinado que mejoran el proceso de obtención de aceituna (Frazier \& Westhoff 1993, Bernabé 2003).

En Tacna se cultiva diferentes variedades de aceituna y se produce aceituna de mesa principalmente de Olea europea var. Sevillana por fermentación en batch. Para esta zona no se tiene reportes del uso de cultivos iniciadores en la fermentación de aceituna; la fermentación que sucede se da en base a la activación de la flora nativa presente en los frutos de olivo que van hacer fermentados dentro del fermentador (Frazier \& Westhoff 1993, Yufra 2001). En otros lugares sobre todo fuera del país para la producción de aceituna negra de mesa se hace empleo de cultivos iniciadores que han permitido una mejora en la producción, productividad y calidad del producto.

En este trabajo se tuvo como objetivo general: Obtener aceituna negra de mesa por fermentación en batch con y sin cultivo iniciador en Tacna-Perú; y como objetivos específicos: evaluar parámetros físicos y químicos de la fermentación y determinar la producción, productividad y calidad de la aceituna.

\section{MATERIAL Y MÉTODOS}

\section{Diseño y construcción de fermentadores:}

Se diseñó fermentadores de 8 litros de capacidad; de forma cilíndrica; con un cuello corto, de $15 \mathrm{~cm}$ de diámetro, en su parte superior lateral; con una tapa removible cribada en su superficie que podía ser encajado dentro del cuello corto y cubierto en su parte superior por una superficie plana; y con una llave para la toma de muestra en la parte inferior lateral externa de la parte cilíndrica del fermentador.

Los fermentadores diseñados se mandaron a construir con material de fibra de vidrio en un número de tres.

\section{Recolección y transporte de la aceituna negra:}

Se recolectó 16 kilogramos de aceituna negra del cultivo de olivo del lugar denominado Los Palos, luego del cual se transportó en bolsas plásticas de primer uso hacia el laboratorio de Micología Virología.

\section{Obtención de curvas patrón de salinidad:}

Se preparó en tubos de ensayo soluciones de sal con volúmenes de $10 \mathrm{ml}$ pesando las cantidades de sal $(\mathrm{NaCl})$ de $0.125 ; 0.25 ; 0.375 ; 0.5 ; 0.625 ; 0.75 ; 0.875$; $1.0 ; 1.125 ; 1.25 ; 1.375 ; 1.5 ; 1.625 ; 1.75$ y $1.875 \mathrm{~g} ; \mathrm{y}$ disolviendo, respectivamente, éstas en $9.875 ; 9.75$; 9.625; 9.5; 9.375; 9.25; 9.125; 9.0; 8.875; 8.75; 8.625; $8.5 ; 8.375 ; 8.25$ y $8.125 \mathrm{ml}$ de agua destilada para obtener en forma correspondiente soluciones de 1.25 ; $2.5 ; 3.75 ; 5 ; 6.25 ; 7.5 ; 8.75 ; 10 ; 11.25 ; 12.5 ; 13.75$; $15.0 ; 16.25 ; 17.5$ y $18.75 \%$.

Luego con ayuda del programa computacional Excel, considerando una figura de coordenadas, los valores de porcentaje de salinidad fueron representados en el eje de las ordenadas y las cantidades de sal en el eje de las abscisas, determinándose enseguida la recta que representó la curva patrón de calibración de salinidad en función del porcentaje de salinidad versus cantidad de sal.

Otras curvas patrón de calibración de salinidad se prepararon a partir de los datos anteriores y de |20aquellos que se obtuvo midiendo los grados Brix $\left({ }^{\circ} \mathrm{Brix}\right)$ y los grados Baumé $\left({ }^{\circ} \mathrm{Be}\right)$ de las soluciones de sal. Estas fueron las que estuvieron: en base a la cantidad de sal versus ${ }^{\circ}$ Brix, para lo cual las cantidades de sal $(0.125 ; 0.25 ; 0.375 ; 0.5 ; 0.625 ; 0.75$; $0.875 ; 1.0 ; 1.125 ; 1.25 ; 1.375 ; 1.5 ; 1.625 ; 1.75$ у $1.875 \mathrm{~g})$ disueltas en agua destilada haciendo volúmenes de $10 \mathrm{ml}$ estuvieron representadas en el eje de las abscisas y los ${ }^{\circ}$ Brix $(1.6 ; 3.0 ; 4.2 ; 5.8 ; 7.0 ; 8.2$; $9.8 ; 11.0 ; 12.8 ; 13.8 ; 15.2 ; 16.4 ; 17.2 ; 19.2$ y 20.4 ${ }^{\circ}$ Brix) en el eje de las ordenadas; en base a la cantidad de sal versus ${ }^{\circ} \mathrm{Be}$, para lo cual las cantidades de sal $(0.125 ; 0.25 ; 0.375 ; 0.5 ; 0.625 ; 0.75 ; 0.875 ; 1.0 ; 1.125$; $1.25 ; 1.375 ; 1.5 ; 1.625 ; 1.75$ y $1.875 \mathrm{~g}$ ) disueltas en agua destilada en volúmenes de $10 \mathrm{ml}$, representadas en el eje de las abscisas y los ${ }^{\circ} \mathrm{Be}(1 ; 2 ; 3 ; 4 ; 5 ; 6 ; 7 ; 8 ; 9$; $\left.10 ; 11 ; 12 ; 13 ; 14 ; \mathrm{y} 15^{\circ} \mathrm{Be}\right)$ en el eje de las ordenadas; $\mathrm{y}$ en base al ${ }^{\circ} \mathrm{Be}$ versus ${ }^{\circ}$ Brix, para lo cual los ${ }^{\circ} \mathrm{Be}(1$; $2 ; 3 ; 4 ; 5 ; 6 ; 7 ; 8 ; 9 ; 10 ; 11 ; 12 ; 13 ; 14$ y $\left.15^{\circ} \mathrm{Be}\right)$ estuvieron representadas en el eje de las abscisas y los ${ }^{\circ} \operatorname{Brix}(1.6 ; 3.0 ; 4.2 ; 5.8 ; 7.0 ; 8.2 ; 9.8 ; 11.0 ; 12.8 ; 13.8$; $15.2 ; 16.4 ; 17.2 ; 19.2$ y $20.4{ }^{\circ}$ Brix) en el eje de las ordenadas. Los ${ }^{\circ}$ Brix de las soluciones de sal se midieron empleando un refractómetro de mano y los ${ }^{\circ}$ Be fue con la fórmula:

Cant. sal necesaria $(\mathrm{g})=\left({ }^{\circ} \mathrm{B}\right.$ deseadosx $1.25 \mathrm{x}$ vol $) / 100$

Donde:

${ }^{\circ}$ Baumé, son los grados con los que se trabajó.

Volumen, el que correspondió a la cantidad de salmuera que se preparó.

1,25: factor empleado que por referencia depende mucho de la pureza y solubilidad de sal empleada.

\section{Preparación de la salmuera:}

Se preparó 18 litros de salmuera al 10\% pesando y disolviendo $1800 \mathrm{~g}$ de sal de cocina $(\mathrm{NaCl})$ en 16.2 litros de agua de caño contenido en un balde de 20 litros. 


\section{Llenado del substrato fermentativo a los fermentadores}

$$
\% \text { Ácido láctico }=\frac{\text { gasto } \times \mathrm{N} \times 9}{\text { Vol. muestra }}
$$

Se agregó 4 kilogramos de aceituna negra seguida de 4.5 litros de salmuera $10 \%$ a cada uno de los tres fermentadores empleados para esta fermentación de tal modo que al ser tapado los fermentadores con la tapa removible cribada el nivel de la salmuera quedó por encima de la superficie de esta tapa removible.

\section{Inoculación con cultivo iniciador al substrato} fermentativo contenido en los fermentadores:

Se inóculo a dos de los tres fermentadores $90 \mathrm{ml}$ de licor madre como cultivo iniciador proveniente de una fermentación de aceituna negra que tuvo una concentración de $28 \times 10^{6}$ bacterias por $\mathrm{ml}$ que al diluirse en el fermentador inoculado originó que la salmuera de estos fermentadores tuvieran $5.6 \times 10^{5}$ bacterias por $\mathrm{ml}$.

\section{Inicio y evaluación de la fermentación:}

Se inició la fermentación incubando los fermentadores, inmediatamente después de la inoculación del cultivo iniciador, a temperatura ambiente del laboratorio; asimismo se dio inicio a la evaluación del substrato fermentativo, cada 14 días en promedio, respecto al $\mathrm{pH}$, la acidez, el grado Brix, la temperatura y el número de microorganismos por mililitro hasta que las aceitunas presentaron características organolépticas aceptables para su consumo y compatible con un valor de $\mathrm{pH}$ y acidez correspondiente al del término de una fermentación de aceituna.

El pH fue evaluado con ayuda de una cinta de papel de pH Universal. La acidez se determinó por titulación simple para lo cual se tomó $1 \mathrm{ml}$ de muestra con la pipeta para ser vertido en un vaso de precipitado en el cual luego se añadió 3 a 5 gotas de fenolftaleína al 1\% para que finalmente se valoró la acidez con $\mathrm{NaOH} 0,1 \mathrm{~N}$ y se registró el valor del gasto el cual se reemplazó en la fórmula siguiente.

$\mathrm{El}^{\circ}$ Brix se evaluó usando un refractómetro de mano, el cual se transformó en ${ }^{\circ} \mathrm{Be}$ utilizando la ecuación de la curva patrón de salinidad ${ }^{\circ}$ Brix vs ${ }^{\circ} \mathrm{Be}$ :

$$
\mathrm{Y}=1.3393 \mathrm{X}+0.3257
$$

Donde $\mathrm{Y}=$ grados Brix, y $\mathrm{X}=$ grados Baumé. Cuando la salinidad y o el volumen de salmuera estuvo por debajo de la concentración o volumen establecido se procedió a corregirse agregando una salmuera lo suficientemente concentrada como para que se restableciera la concentración y o el volumen original. La temperatura se determinó empleando un termómetro de bulbo con mercurio el cual fue introducido dentro de la salmuera en cada medición. El número de bacterias por mililitro de salmuera se determinó con ayuda de una cámara de Neubauer y un microscopio compuesto de campo claro.

\section{Producción y productividad de aceituna negra de} mesa:

La producción de aceituna negra de mesa se determinó pesando la cantidad total de aceituna fermentada. La productividad dividiendo el valor de producción de aceituna fermentada entre el valor del tiempo de fermentación.

\section{Análisis sensorial de la aceituna negra de mesa producida:}

Se llevó a cabo en el laboratorio de micología virología de la Facultad de Ciencias. UNJBG. En este análisis se emplearon 33 jueces los cuales tenían nociones de las características de una aceituna de mesa y se tuvo en cuenta una muestra patrón con la cual se comparó las aceitunas negras de mesa procedentes de los fermentadores sin cultivo iniciador y con cultivo iniciador. Cada juez probó y comparó cada muestra con el patrón y evaluó la diferencia de los atributos entre la muestra y el patrón utilizando una escala comparativa de 7 valores hecha para este propósito. Los atributos que se evaluaron fueron: apariencia externa, olor, sabor y textura.

Las evaluaciones se llevaron a cabo en horas de la mañana (entre las 09 a $12 \mathrm{~h}$ ), cada juez tuvo un tiempo referencial de 10 minutos para realizar su evaluación. El método que se empleó fue el método analítico de laboratorio denominado: Prueba de comparación múltiple o diferencial al control.

En esta prueba se mostró una muestra patrón "P" (muestra de aceitunas obtenidas por una fermentación tradicional que pertenecen al tratamiento SC) y debajo de ésta, dos muestras alineadas y codificadas como 348 para el tratamiento SC (Sin cultivo iniciador) y 553 para el tratamiento $\mathrm{CC}$ (con cultivo iniciador).

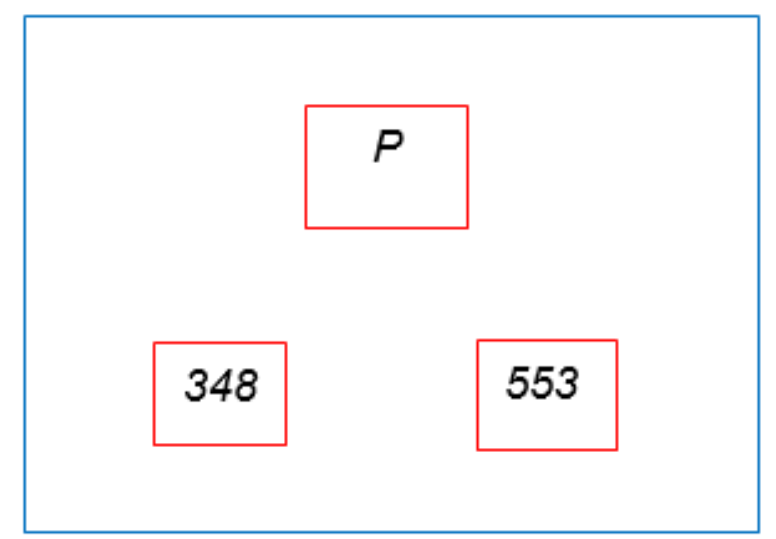

Se pidió a cada juez, probar y comparar cada muestra codificada con el patrón, y evaluar la diferencia de los atributos entre la muestra y el patrón, utilizando una escala comparativa de 7 valores hecha para este propósito. Los atributos que se evaluaron fueron: apariencia externa, olor, sabor y textura. En la evaluación del sabor se empleó agua potable a temperatura ambiente para enjuagar la boca del juez después de degustar cada muestra. Finalmente, el juez llenó una ficha de respuestas o cuestionario. 
Análisis estadístico para los datos obtenidos del análisis sensorial:

Los datos obtenidos del análisis sensorial, fueron procesados basándose en el análisis de varianza (ANOVA) con un nivel de significancia del 5\%. No fue necesario usar la prueba de diferencia

\section{RESULTADOS}

\section{Curvas patrón de salinidad:}

Se muestran los datos trabajados (Tabla 1) para obtener las curvas patrón de salinidad (Figura 1) (Figura 2) (Figura 3) en los cuales se observa para cada curva un $\mathrm{R}^{2}$ (coeficiente de determinación) del análisis de la línea de regresión cercano a 1 .

Tabla 1.

Datos de cantidad de sal, volumen de agua destilada, volumen de salmuera, porcentaje de sal, grados Baumé $\left({ }^{\circ}\right.$ Bé) y grados Brix ( ${ }^{\circ}$ Brix) obtenidos de la salmuera presente en tubos de ensayo que sirvieron para determinar las curvas patrón de salinidad.

\begin{tabular}{|c|c|c|c|c|c|c|}
\hline $\begin{array}{c}\text { Tubo } \\
\text { de } \\
\text { ensayo }\end{array}$ & $\begin{array}{c}\text { Cantidad de } \\
\text { sal } \\
\text { (g) }\end{array}$ & $\begin{array}{c}\begin{array}{c}\text { Agua } \\
\text { destilada }\end{array} \\
\text { (ml) }\end{array}$ & $\begin{array}{c}\text { Sal } \\
\text { muera } \\
(m l)\end{array}$ & $\begin{array}{l}\text { sal } \\
\%\end{array}$ & ${ }^{\circ} \mathrm{Be}$ & ${ }^{\circ}$ Brix \\
\hline 1 & 0.125 & 9.875 & 10 & 1.25 & 1 & 1.6 \\
\hline 2 & 0.25 & 9.75 & 10 & 2.5 & 2 & 3 \\
\hline 3 & 0.375 & 9.625 & 10 & 3.75 & 3 & 4.2 \\
\hline 4 & 0,5 & 9,5 & 10 & 5 & 4 & 5.8 \\
\hline 5 & 0.625 & 9.375 & 10 & 6.25 & 5 & 7 \\
\hline 6 & 0.75 & 9.25 & 10 & 7.5 & 6 & 8.2 \\
\hline 7 & 0.875 & 9.125 & 10 & 8.75 & 7 & 9.8 \\
\hline 8 & 1 & 9 & 10 & 10 & 8 & 11 \\
\hline 9 & 1.125 & 8.875 & 10 & 11.25 & 9 & 12.8 \\
\hline 10 & 1.25 & 8.75 & 10 & 12.5 & 10 & 13.8 \\
\hline 11 & 1.375 & 8.625 & 10 & 13.75 & 11 & 15.2 \\
\hline 12 & 1.5 & 8.5 & 10 & 15 & 12 & 16.4 \\
\hline 13 & 1.625 & 8.375 & 10 & 16.25 & 13 & 17.2 \\
\hline 14 & 1.75 & 8.25 & 10 & 17.5 & 14 & 19.2 \\
\hline 15 & 1.875 & 8.125 & 10 & 18.75 & 15 & 20.4 \\
\hline
\end{tabular}

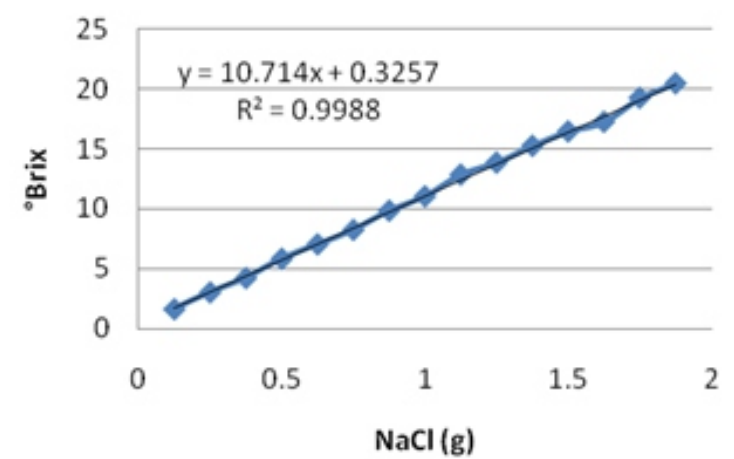

Figura 1. Curva patrón de salinidad cantidad de sal versus ${ }^{\circ}$ Brix.

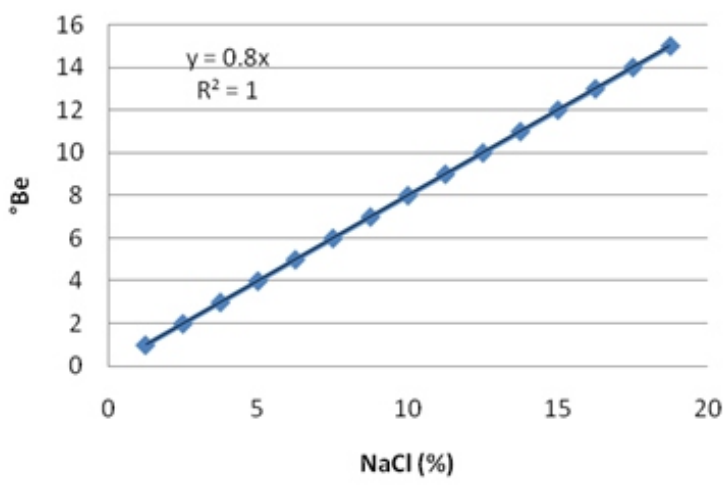

Figura 2. Curva patrón de salinidad porcentaje de sal versus ${ }^{\circ}$ Baumé.

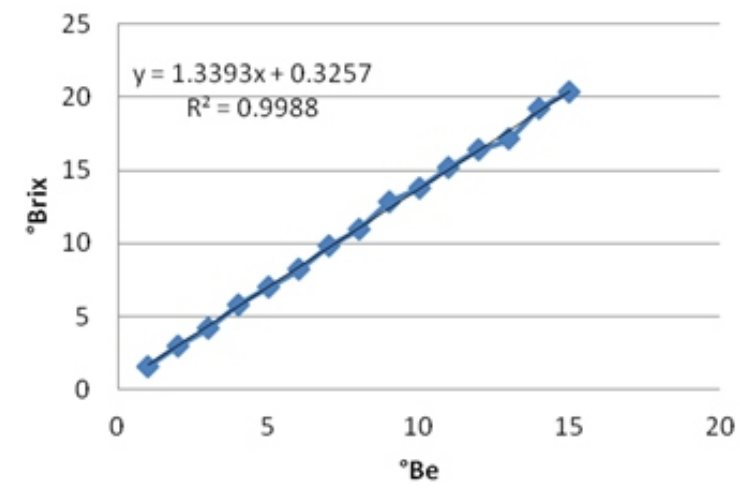

Figura 3. Curva patrón de salinidad ${ }^{\circ} \mathrm{Be} \mathrm{vs}^{\circ} \mathrm{Brix}$.

\section{Fermentadores construidos:}

Se muestra uno de los tres fermentadores que tuvieron el mismo diseño en cuanto a forma, dimensiones y naturaleza del material que lo compone, construido para el experimento (Foto 1). 


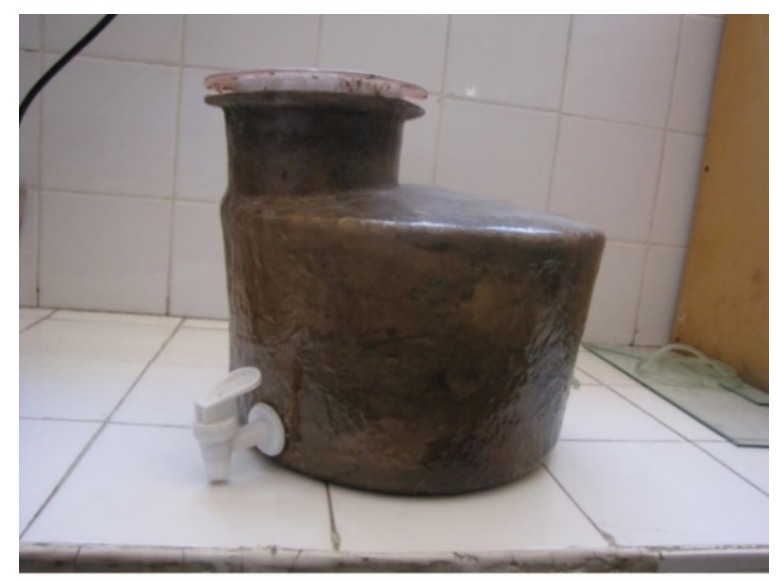

FOTO 1. Fermentador diseñado y construído para la fermentación de la aceituna negra.

\section{FERMENTACIÓN DE LAACEITUNANEGRA:}

Se muestra los fermentadores en pleno proceso de fermentación conteniendo la salmuera, la aceituna negra y el cultivo iniciador (Foto 2).

\section{Parámetros evaluados en la fermentación:}

pH: Se muestra desde el inicio hasta el término de la fermentación (64 días) la tendencia de descenso del pH desde 6.0 a 4.0 en el fermentador sin y con cultivo iniciador; con una mayor acentuación de descenso, desde 6.0 a 5.0 de $\mathrm{pH}$, en los primeros 28 días (Cuadro 1)(Figura 4).

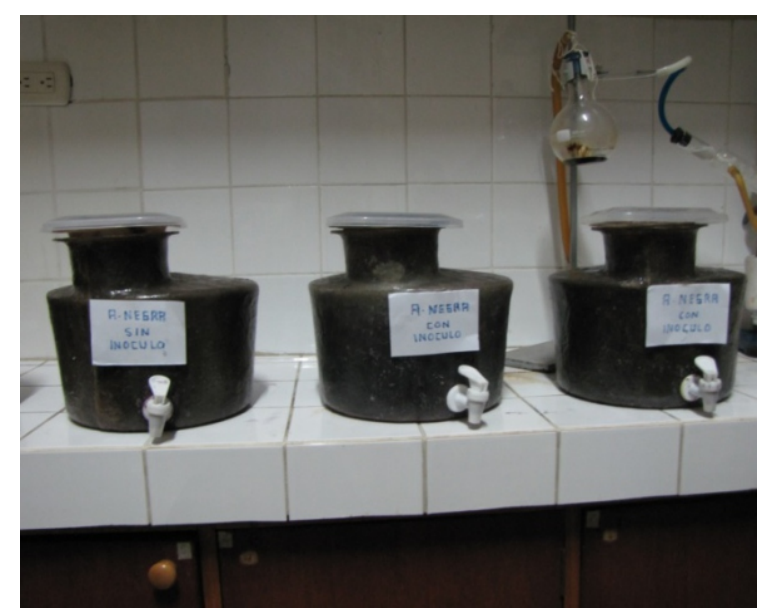

FOTO 2. Fermentadores sin y con cultivo iniciador en pleno proceso de fermentación de la aceituna negra.

ACIDEZ: Se muestra desde el inicio hasta el término de la fermentación (64 d) la tendencia de incremento de la acidez en el fermentador sin y con cultivo iniciador; con un mayor incremento entre los 20 y 40 d de fermentación, mostrandose asi mismo mayor producción de ácidez en donde hubo cultivo iniciador (2.01\% acido láctico) (Tabla 2)(Figura 5).

CONCENTRACIÓN DE SAL EN GRADOS BAUMÉ: Se muestra desde el inicio hasta el término de la fermentación (64 días) la tendencia de mantenerse constante la concentración de sal (entre 6.5 a $7.7^{\circ} \mathrm{Be}$ ) en el fermentador sin y con cultivo iniciador; con una ligera menor concentración de sal a lo largo del proceso en el fermentador con cultivo iniciador (Tabla 3)(Figura 6).

TEMPERATURA: Se muestra desde el inicio hasta el término de la fermentación (64 dias) la tendencia de mantenerse constante la temperatura $\left(\right.$ de 12 a $\left.14^{\circ} \mathrm{C}\right)$ en el fermentador sin y con cultivo iniciador (Tabla 4)(Figura 7).

\section{Número de bacterias por mililitro de salmuera}

Se muestra desde el inicio hasta el término de la fermentación (64 días) la tendencia de incremento del número de bacterias hasta aproximadamente los 40 primeros días con un mantenimiento alrededor del valor más alto alcanzado en los días siguientes en el fermentador sin y con cultivo iniciador; mostrándose un más rápido incremento y un mayor valor del número de bacterias por mililitro $\left(4.3 \times 10^{7}\right.$ bact $\left.\mathrm{ml}^{-1}\right)$ en el fermentador con cultivo iniciador (Tabla 5)(Figura 8).

Tabla 1. pH determinado en la fermentación de aceituna negra en los fermentadores sin y con cultivo iniciador (junio-agosto).

\begin{tabular}{|c|c|c|c|c|}
\hline \multirow{2}{*}{$\begin{array}{c}\text { Tiempo } \\
\text { (d) }\end{array}$} & $\begin{array}{c}\mathrm{pH} \text { en } \\
\text { fermentador } \\
\text { sin cultivo } \\
\text { iniciador }\end{array}$ & \multicolumn{2}{|c|}{$\begin{array}{c}\mathrm{pH} \text { en } \\
\text { cultivo iniciador }\end{array}$} \\
\cline { 3 - 5 } & $\begin{array}{c}\text { Ferm. } \\
\mathrm{N}^{\circ} 1\end{array}$ & $\begin{array}{c}\text { Ferm. } \\
\mathrm{N}^{\circ} 2\end{array}$ & $\begin{array}{c}\mathrm{pH} \\
\text { promedio }\end{array}$ \\
\hline 0 & 6.0 & 6.0 & 6.0 & 6.0 \\
\hline 15 & 5.0 & 5.0 & 5.0 & 5.0 \\
\hline 28 & 4.0 & 4.0 & 4.0 & 4.0 \\
\hline 43 & 4.0 & 4.0 & 4.0 & 4.0 \\
\hline 57 & 4.0 & 4.0 & 4.0 & 4.0 \\
\hline 64 & 4.0 & 4.0 & 4.0 & 4.0 \\
\hline
\end{tabular}

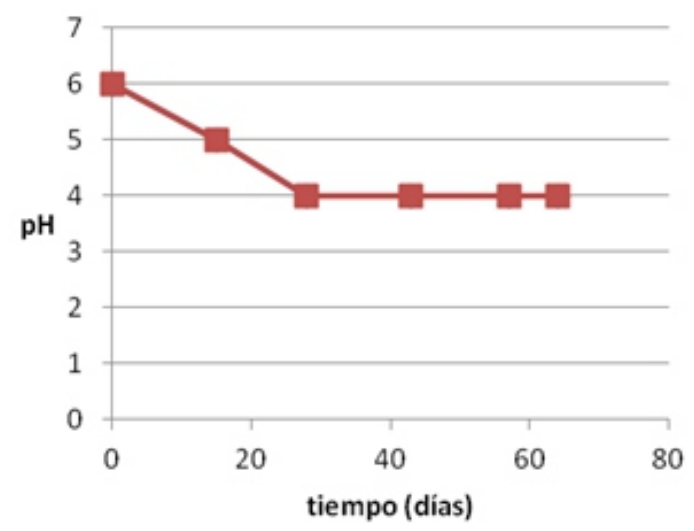

Figura 4. $\mathrm{pH}$ a través de todo el proceso de fermentación de aceituna negra.

Tabla 2. Valores de $\mathrm{pH}$ determinados en la fermentación de aceituna negra en los fermentadores sin cultivo y con cultivo iniciador (junio-agosto). 


\begin{tabular}{|c|c|c|c|c|}
\hline \multirow[b]{2}{*}{$\begin{array}{c}\text { Tiempo } \\
\text { (días) }\end{array}$} & \multirow{2}{*}{$\begin{array}{l}\text { \% Acidez en } \\
\text { ac. láctico } \\
\text { en } \\
\text { fermentador } \\
\text { Sin cultivo } \\
\text { iniciador }\end{array}$} & \multicolumn{3}{|c|}{$\begin{array}{c}\text { \% acidez en ac. láctico en } \\
\text { fermentador } \\
\text { con cultivo iniciador }\end{array}$} \\
\hline & & $\begin{array}{c}\text { Ferm. } \\
\mathrm{N}^{\circ} 1\end{array}$ & $\begin{array}{l}\text { Ferm. } \\
\mathrm{N}^{\circ} 2\end{array}$ & $\begin{array}{c}\% \text { Acidez } \\
\text { promedio }\end{array}$ \\
\hline 0 & 0.10 & 0.16 & 0.12 & 0.14 \\
\hline 15 & 0.90 & 1.28 & 1.20 & 1.24 \\
\hline 28 & 1.71 & 1.96 & 1.94 & 1.95 \\
\hline 43 & 1.82 & 2.01 & 2.00 & 2.00 \\
\hline 57 & 1.98 & 1.99 & 2.01 & 2.00 \\
\hline 64 & 1.96 & 2.00 & 2.02 & 2.01 \\
\hline
\end{tabular}

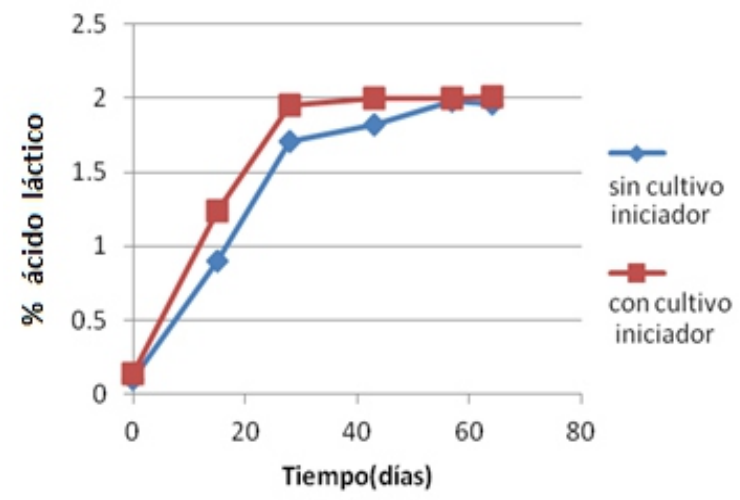

Figura 5. Evolución de la acidez a través del proceso de fermentación de aceituna negra.

Tabla 3. Valores de ${ }^{\circ}$ be en la fermentación de aceituna negra en los fermentadores sin cultivo y con cultivo iniciador.

\begin{tabular}{|c|c|c|c|c|}
\hline & \multirow{2}{*}{$\begin{array}{c}{ }^{\circ} \text { Be en } \\
\text { fermentador } \\
\text { Tiempo }\end{array}$} & \multicolumn{3}{|c|}{$\begin{array}{c}{ }^{\circ} \text { Be en fermentador } \\
\text { con cultivo iniciador }\end{array}$} \\
\cline { 3 - 5 } (días) & $\begin{array}{c}\text { cultivo } \\
\text { iniciador }\end{array}$ & $\begin{array}{c}\text { Ferm. } \\
\mathrm{N}^{\circ} 1\end{array}$ & $\begin{array}{c}\text { Ferm. } \\
\mathrm{N}^{\circ} 2\end{array}$ & $\begin{array}{c}{ }^{\circ} \text { Be } \\
\text { promedio }\end{array}$ \\
\hline 0 & 7.6 & 8.0 & 7.4 & 7.7 \\
\hline 15 & 7.1 & 7.1 & 7.1 & 7.1 \\
\hline 28 & 7.2 & 7.5 & 7.2 & 7.4 \\
\hline 43 & 7.2 & 6.9 & 6.0 & 6.5 \\
\hline 57 & 7.2 & 7.8 & 7.2 & 7.5 \\
\hline 64 & 7.3 & 7.4 & 7.4 & 7.4 \\
\hline
\end{tabular}

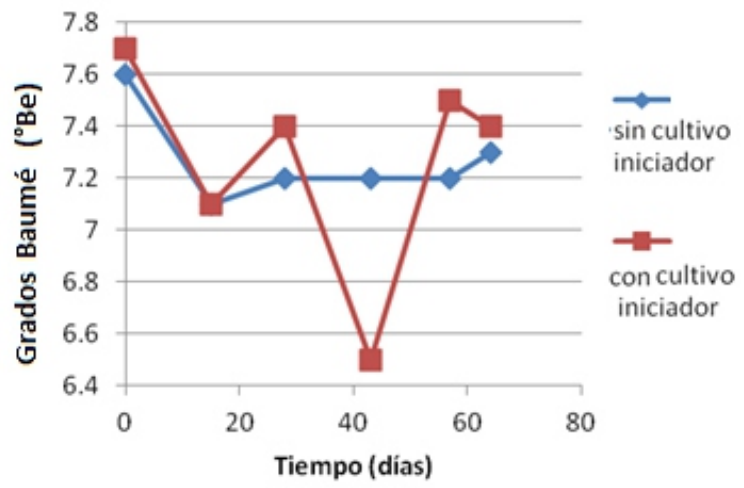

Figura 6. Evolución de los ${ }^{\circ} \mathrm{Be}$ en todo el proceso de fermentación de aceituna negra.

Tabla 4. Temperatura $\left({ }^{\circ} \mathrm{C}\right)$ en la fermentación de aceituna negra en los fermentadores sin cultivo y con cultivo iniciador.

\begin{tabular}{|c|c|c|c|c|}
\hline \multirow[b]{2}{*}{$\begin{array}{l}\text { Tiempo } \\
\text { (días) }\end{array}$} & \multirow{2}{*}{$\begin{array}{c}\text { Fermentador } \\
\text { sin cultivo } \\
\text { iniciador } \\
\left({ }^{\circ} \mathrm{C}\right)\end{array}$} & \multicolumn{3}{|c|}{$\begin{array}{l}\text { Fermentador con cultivo } \\
\text { iniciador }\left({ }^{\circ} \mathrm{C}\right)\end{array}$} \\
\hline & & $\begin{array}{c}\text { Ferm. } \\
\mathrm{N}^{\circ} 1\end{array}$ & $\begin{array}{l}\text { ferm. } \\
n^{\circ} 2\end{array}$ & $\begin{array}{c}{ }^{\circ} \mathrm{C} \\
\text { promedio }\end{array}$ \\
\hline 0 & 14 & 14 & 14 & 14 \\
\hline 15 & 12 & 12 & 12 & 12 \\
\hline 28 & 12 & 12 & 12 & 12 \\
\hline 43 & 12 & 12 & 12 & 12 \\
\hline 57 & 13 & 13 & 13 & 13 \\
\hline 64 & 13 & 13 & 13 & 13 \\
\hline
\end{tabular}

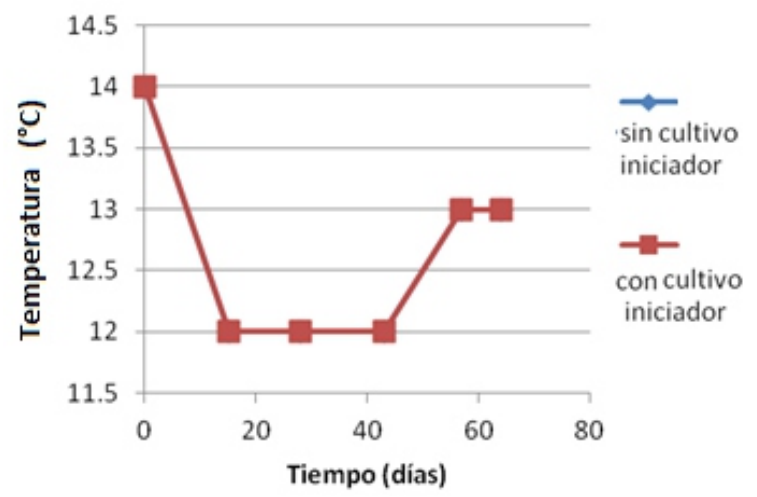

Figura 7. Evolución de la temperatura a través de todo el proceso de fermentación de aceituna negra. 
Tabla 5. Número de bacterias $\mathrm{ml}^{-1}$ en la fermentación de aceituna negra en los fermentadores sin cultivo y con cultivo iniciador.

\begin{tabular}{|c|c|c|c|c|}
\hline \multirow{2}{*}{$\begin{array}{c}\text { Tiempo } \\
\text { (días) }\end{array}$} & $\begin{array}{c}\text { Fermentador } \\
\text { Sin cultivo } \\
\text { iniciador } \\
\left(\mathrm{N}^{\circ} \text { bact } \mathrm{ml}^{-1}\right)\end{array}$ & \multicolumn{3}{|c|}{$\begin{array}{c}\text { Fermentador con cultivo } \\
\text { iniciador }\left(\mathrm{N}^{\circ} \text { bacterias } \mathrm{ml}^{-1}\right)\end{array}$} \\
\cline { 3 - 5 } & $\begin{array}{c}\text { Ferm. } \\
\mathrm{N}^{\circ}\end{array}$ & $\begin{array}{c}\text { Ferm. } \\
\mathrm{N}^{\circ} 2\end{array}$ & $\begin{array}{c}\mathrm{N}^{\circ} \text { bact/ml } \\
\text { promedio }\end{array}$ \\
\hline 0 & $0.0 \mathrm{E} 0$ & $5.6 \mathrm{E} 5$ & $5.6 \mathrm{E} 5$ & $5.6 \mathrm{E} 5$ \\
\hline 15 & $2.6 \mathrm{E} 7$ & $3.0 \mathrm{E} 7$ & $2.1 \mathrm{E} 7$ & $2.6 \mathrm{E} 7$ \\
\hline 28 & $3.6 \mathrm{E} 7$ & $2.8 \mathrm{E} 7$ & $1.7 \mathrm{E} 7$ & $2.3 \mathrm{E} 7$ \\
\hline 43 & $2.0 \mathrm{E} 7$ & $4.8 \mathrm{E} 7$ & $3.8 \mathrm{E} 7$ & $4.3 \mathrm{E} 7$ \\
\hline 57 & $2.7 \mathrm{E} 7$ & $3.0 \mathrm{E} 7$ & $2.1 \mathrm{E} 7$ & $2.6 \mathrm{E} 7$ \\
\hline 64 & $4.2 \mathrm{E} 7$ & $3.7 \mathrm{E} 7$ & $3.7 \mathrm{E} 7$ & $3.7 \mathrm{E} 7$ \\
\hline
\end{tabular}

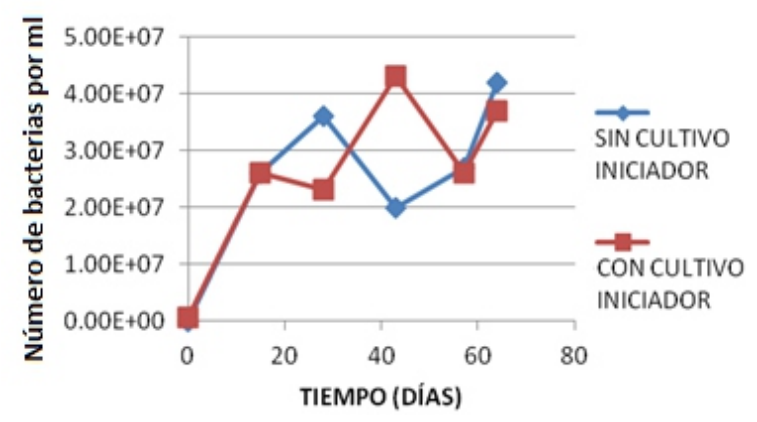

Figura 8. Evolución del número de bacterias por mililitro a través de todo el proceso de fermentación de aceituna negra.

Producción y productividad de aceituna negra de mesa:

Se obtuvo una producción de $4.2 \mathrm{~kg}$ de aceituna negra de mesa y una productividad de $0.07 \mathrm{~kg} \mathrm{día}^{-1}$.

\section{Análisis sensorial de la aceituna negra de mesa} producida:

Se determinó que los atributos sabor y textura en las aceitunas negras de mesa con y sin cultivo iniciador fueron aceptables, pero sin diferencia estadísticamente significativa entre los dos tratamientos (sin y con cultivo iniciador).

\section{DISCUSIÓN}

La fermentación llevada a cabo ha sido un proceso que se desarrolló anaeróbicamente por ello se ha obtenido producción de aceituna negra de mesa. La aceituna de mesa es un producto de fermentación anaeróbica (Jagnow 1991, Madigan 1998).

El tiempo de 64 días empleado en la fermentación de la aceituna negra es menor al de 96 días reportado para algunos casos; así mismo es un valor que está dentro del tiempo de 2 a 3 meses reportado en forma general para la fermentación de aceituna.

Producto de las evaluaciones durante la fermentación las tendencias mostradas con valores menores en el pH y valores mayores en la acidez y en el número de bacterias en los fermentadores con cultivo iniciador son resultados que se han dado en otras fermentaciones con empleo de cultivo iniciador más no en las fermentaciones sin cultivo iniciador. Las tendencias mostradas con los valores casi constantes en la concentración de sal y la temperatura en los fermentadores con y sin cultivo iniciador son resultados que también han sido reportados para otras fermentaciones similares.

La producción y productividad alcanzada en estas fermentaciones nos indica respectivamente la buena producción alcanzada, porque no hubo ninguna cantidad de aceituna fermentada desechada y el empleo de poco tiempo para la fermentación dado que se realizó en el tiempo menor del intervalo de 2 a 3 meses reportado en forma general como tiempo de fermentación de la aceituna (Gallegos 2005, Bernabé 2003).

La ausencia de diferencia estadística significativa para los atributos apariencia externa, olor, sabor y textura en la aceitunas de los tratamientos con y sin cultivo iniciador nos indica que la aceituna producida en cuanto a características sensoriales ha sido indiferente al uso del cultivo iniciador lo cual no significa que el cultivo iniciador no haya ejercido ningún efecto benéfico a la fermentación (Espinoza, 2000); dado que en otros parámetros como el de la acidez; donde ha habido cultivo iniciador la concentración de acidez en el fermentador ha sido mayor, esto es muy importante para un mayor tiempo de conservación natural de la aceituna. Esto último refleja la importancia que tiene el cultivo iniciador en la fermentación de la aceituna. Se sabe que los cultivos iniciadores tienen influencia en las características físicas, químicas y organolépticas de las aceitunas fermentadas, siendo variable el grado de influencia según el tipo de cultivo iniciador (Bernabé 2003).

\section{CONCLUSIONES}

En los parámetros físicos químicos evaluados en la fermentación (64 días) el pH tuvo una tendencia de descenso desde 6.0 a 4.0; la acidez una tendencia de ascenso de 0.1 a $2.01 \%$ ácido láctico con mayor producción de acidez donde hubo cultivo iniciador; la concentración de sal una tendencia de mantenimiento constante entre 6.5 a $7.7^{\circ} \mathrm{Be}$ con un valor ligeramente menor donde hubo cultivo iniciador; la temperatura una tendencia de mantenimiento constante entre 14 y $12{ }^{\circ} \mathrm{C}$; el número de bacterias por mililitro de salmuera una tendencia inicial de incremento seguida de mantenimiento en un valor menor, con una ligera mayor concentración de bacterias donde hubo inóculo $\left(4.3 \times 10^{7}\right.$ bact $\left.\mathrm{ml}^{-1}\right)$.

La producción fue de $4.2 \mathrm{~kg}$ de aceituna negra de mesa con una productividad de $0.07 \mathrm{~kg} \mathrm{día}{ }^{-1}$.

Los atributos apariencia externa, olor, sabor y textura fueron aceptables, pero no tuvieron diferencia estadísticamente significativa para los dos tratamientos de la experimentación (con y sin cultivo iniciador).

\section{RECOMENDACIONES}

Continuar investigando la influencia de otros factores como el de cepas de bacterias lácticas específicas puras como cultivo iniciador, el agregado simultáneo de 
ácidos orgánicos con cepas bacterianas lácticas específicas a fin de obtener mejores productividades y atributos de la aceituna negra de mesa.

\section{REFERENCIAS BIBLIOGRÁFICAS}

BERNABE C., L. MANUEL. 2003. Evaluación de la calidad sensorial de la aceituna de mesa tipo negra obtenida mediante el empleo de ácido acético y cultivo iniciadores de Lactobacillus plantarum nativos. Tesis. ESBI. FACI. UNJBG. Tacna-Perú.

BROCK. 2012. Biology of microorganisms. 13 ava. Edition. Edit. Pearson. San Francisco. E.E.U.U.

DORAN P.M. 1998. Principio de Ingeniería de los Bioprocesos. Edit. Acribia, S.A. España.

ESPINOZA E. 2000. Análisis sensorial avanzada de los alimentos. Escuela de Postgrado de la Universidad Nacional Jorge Basadre Grohmann. Tacna-Perú.

FRAZIER W.C. \& D.C. WESTHOFF. 1993. Microbiología de los alimentos. Cuarta Edición. Edit. Acribia, S.A. Zaragoza. España.

GALLEGOS A. \& MARTHA. 2005. Manual de procesamiento de aceitunas de mesa. CYTE Agroindustrial. Tacna-Perú.
GARRIDO A. \& P. GARCÍA. 1988. Fermentación de la aceituna. Sevilla. España.

GODFREY T. \& J. REICHELT. 1983. Industrial Enzymology: The application of enzymes in industry. Edit. The Nature Press. New York.

HERNANDEZ N.A. 1994. Depuración de Aguas residuales. Edic. 3ra. Edit. Paraninfo, S.A. Madrid. España.

JAGNOW G. \& W. DAWID. 1991. Biotecnología. Edit. Acribia, S.A. Zaragoza. España.

KENNETH C. FUGELSANG \& CHARLES G. EDWARDS. 2007. Wine microbiology. Practical Applications and Procedures. Second edition. Edit. Springer. New York. U.S.A.

MADIGAN M.T. Y COL. 1998. Biología de los microorganismos. Edic. 8ra. Edit. Prentice Hall. España.

QUINTEROS R. R. 1981. Ingeniería bioquímica. Edit. Alhambra Mexicana, S.A. México.

SMITH C.A. \& E.J. WOOD. 1998. Energía en los sistemas biológicos. Edit. Addison-Wesley Iberoamericana, S.A. Delaware. E.U.A.

YUFRA P. VELIA. 2001. Procesamiento de la Aceituna negra natural en el valle de Yauca, Arequipa. Perú. DESCO. Boletín $\mathrm{N}^{\circ} 02$ 